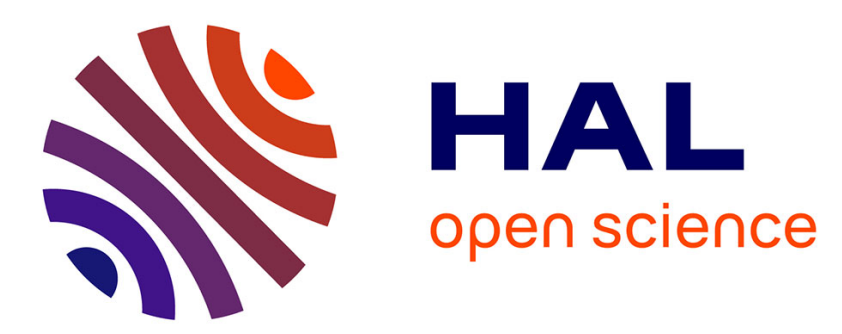

\title{
Effect of the wick characteristics on the thermal behaviour of a LHP capillary evaporator
}

\author{
R. Giraudon, S. Lips, D. Fabrègue, Laurent Gremillard, E. Maire, V. Sartre
}

\section{To cite this version:}

R. Giraudon, S. Lips, D. Fabrègue, Laurent Gremillard, E. Maire, et al.. Effect of the wick characteristics on the thermal behaviour of a LHP capillary evaporator. International Journal of Thermal Sciences, 2018, 133, pp.22-31. 10.1016/j.ijthermalsci.2018.07.003 . hal-01858426

\section{HAL Id: hal-01858426 \\ https://hal.science/hal-01858426}

Submitted on 20 Mar 2019

HAL is a multi-disciplinary open access archive for the deposit and dissemination of scientific research documents, whether they are published or not. The documents may come from teaching and research institutions in France or abroad, or from public or private research centers.
L'archive ouverte pluridisciplinaire HAL, est destinée au dépôt et à la diffusion de documents scientifiques de niveau recherche, publiés ou non, émanant des établissements d'enseignement et de recherche français ou étrangers, des laboratoires publics ou privés. 


\title{
Effect of the wick characteristics on the thermal behaviour of a LHP capillary evaporator
}

\author{
R. Giraudon ${ }^{\mathrm{a}}$, S. Lips ${ }^{\mathrm{a}}$, D. Fabrègue ${ }^{\mathrm{b}}$, L. Gremillard ${ }^{\mathrm{b}}$, E. Maire ${ }^{\mathrm{b}}$, V. Sartre \\ ${ }^{a}$ Univ Lyon, CNRS, INSA-Lyon, CETHIL UMR5008, F-69621, Villeurbanne, France \\ ${ }^{b}$ Univ Lyon, CNRS, INSA-Lyon, MATEIS UMR5510, F-69621, Villeurbanne, France
}

\begin{abstract}
The present work aims at investigating the effect of the characteristics of porous wicks integrated in a flat diskshaped LHP evaporator on their thermal performance and operating limits. Several wicks were manufactured by sintering of copper powder following a design of experiment, and characterised in terms of permeability, porosity, pore radius and thickness. A specific test bench was designed, consisting of a LHP evaporator uncoupled from the condenser. Water and pentane were used as the working fluids. The theoretical capillary and boiling limits of the wicks in the test bench were studied and compared to the experimental data. It was observed that a high permeable wick $\left(K>10^{-13} \mathrm{~m}^{2}\right)$ is likely to reach the boiling limit before the capillary limit because the fluid easily percolates through it. The heat transfer coefficient between the evaporator wall and the evaporating fluid is significantly higher with pentane than with water. It reaches a maximum value of $2340 \mathrm{~W} \cdot \mathrm{m}^{-2} . \mathrm{K}^{-1}$ with water and $5310 \mathrm{~W} \cdot \mathrm{m}^{-2} \cdot \mathrm{K}^{-1}$ with pentane, but no clear tendency could be highlighted concerning the effect of the wick characteristics on this parameter. The maximum dissipated heat transfer rate before the wick dry-out varies in a smaller range with pentane than with water. The highest measured values are equal to $88 \mathrm{~kW} . \mathrm{m}^{-2}$ with water and
\end{abstract} $56 \mathrm{~kW} \cdot \mathrm{m}^{-2}$ with pentane.

Keywords: loop heat pipe evaporator; sintered copper wick; hydrodynamic characteristics; heat transfer coefficient; capillary limit; boiling limit; water; pentane

\section{Introduction}

A loop heat pipe (LHP) is an efficient heat transfer device mainly used in electronic applications to transfer the heat from a very confined space to a larger heat sink. The evaporator is an important component of such a system, its efficiency being closely linked to its design. The heat dissipated by the electronic component is transferred by evaporation to the working fluid at the surface of a wick located against the heated wall. The wick, often made of a sintered metallic powder, acts as a capillary pump, enabling the fluid to flow from the condenser to the reservoir. Thus, a fluid circulation is established around the loop, providing that the capillary forces are sufficient to overcome the whole pressure drops.

The operating limits that are the most likely to occur in a LHP are the capillary and the boiling limits (Cimbala et al. [1], $\mathrm{Ku}$ [2]). The former is reached when the maximum capillary pressure is reached in the wick whereas the latter is due to a too high superheat creating a vapour zone inside the porous structure. Since visual observation inside the evaporator of a LHP is difficult, achieving an accurate understanding of the phenomena acting in the capillary structure remains nowadays an issue. Moreover, 
these phenomena are strongly coupled to the ones occurring in the other parts of the loop (Launay et al. [3]). Uncoupling the evaporator from the rest of the loop would enable to investigate these phenomena and to characterise the intrinsic thermal performance and operating limits of the wick inside the evaporator.

In the literature, only few experimental studies are related to an isolated LHP evaporator. The identified test benches reproduced either the whole LHP evaporator-reservoir or just a part of it, made of a single fin and a single groove facing the wick. Zhao and Liao ([4], [5]) as well as Khammar et al. [6] and Schertzer et al. [7] experimentally studied the heat transfer between the whole flat-disk shaped evaporator wall and the wick. They used various porous structures with a particle diameter ranging from $0.05 \mathrm{~mm}$ to $1.09 \mathrm{~mm}$. The measured heat transfer coefficient at the evaporator, defined as the heat flux density divided by the difference between the mean wall temperature at the fin tips and the saturation temperature, ranged from $7000 \mathrm{~W} \cdot \mathrm{m}^{-2} \cdot \mathrm{K}^{-1}$ to $69000 \mathrm{~W} \cdot \mathrm{m}^{-2} \cdot \mathrm{K}^{-1}$. The maximum heat flux densities ranged from $135 \mathrm{~kW} \cdot \mathrm{m}^{-2}$ to $200 \mathrm{~kW} \cdot \mathrm{m}^{-2}$.

Contrary to what happens in a whole LHP, the operating conditions of such isolated evaporators can be well controlled. Indeed, the wick can be fed with liquid coming from a reservoir equipped with a temperature controller. However, the capabilities of the various test benches described in the literature differ strongly. For instance, the test bench of Zhao and Liao ([4], [5]) enabled a visualisation of the fluid behaviour at the vicinity of the fin through a window located at the surface of the evaporator. However, the loop was open to the atmosphere preventing to adjust the pressure inside the bench. Delil and Baturkin [8] reproduced a LHP without any liquid line and where the reservoir also plays the role of a condenser in order to reduce its influence on the evaporator behaviour. Since the system is closed and tight, the saturation temperature can be easily modified. However, no visualisations were possible with this set up.

Some set-ups also enabled to focus on a specific phenomenon. For instance, Khammar et al. [6] and Schertzer et al. [7] studied the influence of a gap between the porous wick and the evaporator grooves. Both authors found that a gap increases the thermal performance of a capillary evaporator. Mottet et al. [9] designed another kind of test bench reproducing a single fin and part of a wick, made with a random distribution of transparent beads. Since the front face of the device is also transparent, they experimentally observed the development of the vapour zone in quasi $2 \mathrm{D}$ conditions. The results are in good accordance with a pore network model proposed in the same paper. For low and moderate heat fluxes, a steady state can be reached even with the presence of a vapour pocket under the fin, as predicted by Zhao and Liao [4]. Recently, Kumar et al. [10] tracked the location liquid-vapour interface in their wick heated by a single fin using infrared thermography.

Hence, it appears that the pore size and more broadly, the wick characteristics, affect the operating limits encountered in LHP evaporators [11]. It highlights the motivation of authors to work on the fabrication of new wicks with advanced features, able to delay the development of the vapour inside the porous structure or able to evacuate it more easily. They also aim at limiting the heat leak to the reservoir [12]. These wicks can be biporous (Yeh et al. [13], Li et al. [14], Liu et al. [15], Chen et al., ([16], [17])), bidispersed (Yu and Cheng [18], Chen et al. [19]), bi-layered (Wu et al. [20], Xu et al. [21]) or threelayered (Ji et al. [22]). However, very few experimental studies were performed to methodically investigate the effect of the characteristics of the porous structure on the evaporator operating limits.

The objective of this work is to investigate the thermal behaviour of a bi-layer capillary structure for which the manufacturing process and the characterisation procedure are perfectly controlled. In a first section, the manufacturing and characterisation of a wick layer made of sintered metal powder 
specifically dedicated to be in contact with a flat disk-shaped LHP grooved evaporator wall, of internal diameter $4 \mathrm{~mm}$, are detailed. Copper is chosen as the wick material since it has a high thermal conductivity enabling to transfer high heat fluxes from the evaporator wall to the fluid. Then, the experimental apparatus is described and a theoretical analysis of the operating limits is proposed. Finally, the investigation of the thermal performance exhibited by these structures and of the occurrence of operating limits when submitted to a high heat load is conducted. Two working fluids are used, water and pentane, to compare these phenomena for different fluid properties.

\section{Manufacturing and characterisation of the wicks}

In order to investigate the influence of the wick hydrodynamic characteristics on its thermal performance, a design of experiment proposed by Montgomery [23] was used. The manufacturing process enabling to obtain porous wicks following this design of experiment was deeply described by Giraudon et al. [24] and is only briefly summarized here. A copper powder, previously mixed with a binder to obtain a slurry, was partially sintered with a different combination of the four sintering parameters for each experiment, the parameters being the forming pressure $P_{f}$, the mass of sintered powder $m_{s}$, the sintering temperature $T_{s i n}$ and the sintering time $t_{s i n}$. The minimum (sign -) and maximum $($ sign +$)$ values of each parameter, as well as the various sets of parameter considered in the design of experiment, are presented in Table 1. The sintering being realised in a furnace at ambient atmosphere, the copper is oxidised during the process.

Table 1: Sets of parameters used to manufacture the wicks

\begin{tabular}{|l|c|c|c|c|}
\hline Param. & $\boldsymbol{P}_{f}[\mathbf{M P a}]$ & $\boldsymbol{m}_{\boldsymbol{s}}[\mathrm{g}]$ & $\boldsymbol{T}_{\boldsymbol{s i n}}\left[{ }^{\circ} \mathbf{C}\right]$ & $\boldsymbol{t}_{\boldsymbol{s i n}}[\mathbf{m i n}]$ \\
\hline Max (+) & 35 & 25 & 900 & 120 \\
\hline Min (-) & 7 & 10 & 800 & 30 \\
\hline
\end{tabular}

\begin{tabular}{|c|c|c|c|c|}
\hline Set & $\boldsymbol{P}_{\boldsymbol{f}}$ & $\boldsymbol{m}_{\boldsymbol{s}}$ & $\boldsymbol{T}_{\text {sin }}$ & $\boldsymbol{t}_{\text {sin }}$ \\
\hline 1 & - & - & - & - \\
\hline 2 & + & - & - & + \\
\hline 3 & - & + & - & + \\
\hline 4 & + & + & - & - \\
\hline 5 & - & - & + & + \\
\hline 6 & + & - & + & - \\
\hline 7 & - & + & + & - \\
\hline 8 & + & + & + & + \\
\hline
\end{tabular}

The characterisation of the wicks in terms of thickness, porosity, permeability and pore radius were performed following the procedures proposed by Giraudon et al. [24]. The thickness $e_{w}$ as well as the diameter were measured with a calliper. The porosity $\varepsilon$ was determined by measuring the volume $V_{w}$ (from the thickness and the diameter) and the mass $m_{w}$ of each sample:

$$
\varepsilon=1-\frac{m_{w}}{\rho_{s} V_{w}}
$$

where $\rho_{s}$ is the density of the copper powder.

A specific test bench, described by Giraudon et al. [24] and based on a fixed hydrostatic pressure difference $\Delta P_{w}$ across the wick enabled to determine the permeability $K$ and the effective pore radius $r_{p, e f f}$ of each sample. 
The former is determined by means of the Darcy's law inside the porous structure:

$$
K=\frac{\Delta P_{w}}{u_{D a r c y} \mu_{l} e_{w}}
$$

where $\mu_{l}$ is the liquid viscosity and $u_{\text {Darcy }}$ the Darcy's liquid velocity in the wick.

The later represents the minimum radius of interconnection between the pores and can be determined with the maximum capillary pressure sustainable by the wick $\Delta P_{c a p, \max }$ :

$$
r_{p, e f f}=\frac{2 \sigma \cos \theta}{\Delta P_{c a p, \max }}
$$

$\sigma$ is the fluid surface tension and $\theta$ is the contact angle between the fluid and the pore wall. The later was measured by deposing a liquid droplet on an oxidised copper surface. It is equal to $5^{\circ}$ with pentane and to $51^{\circ}$ with water. To complete the effective pore radius measurements, the geometric pore radius $r_{p}$ was also estimated by means of SEM or microscopic views (Figure 1). For each sample, the radii of 10 to 20 pores were measured and averaged.

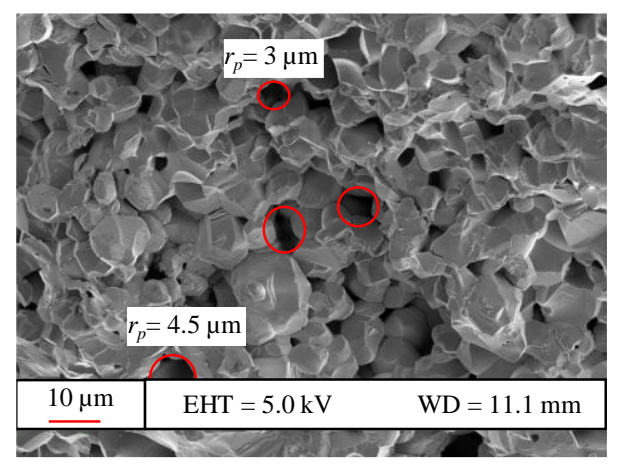

Figure 1: Example of pore radius measurements

In order to study the reproducibility of the manufacturing procedure, several porous wicks were manufactured using the same sets of parameters. Figure 2 presents the measurements of the thickness $e_{w}$, the porosity $\varepsilon$, the permeability $K$ and the effective pore radius $r_{p, e f f}$ obtained with samples for which reproducibility tests were performed. There is a lack of results concerning the effective pore radius and the permeability because the manufacturing sometimes led to diameters incompatible with the experimental apparatus or because some samples were broken after the sintering due to their mechanical brittleness.

It can be concluded that the manufacturing procedures enable to obtain reproducible porosities and permeabilities. However, the effective pore radius seems less reproducible. It can be explained by the fact that, contrary to the other characteristics, it is governed by the local microstructure of the porous medium. Indeed, it represents the smallest interconnection radius from the top of the wick to the bottom. As the structures are heterogeneous, this parameter is more likely to take different values from a sample to another one than the global characteristics like the permeability and the porosity. To a less extent, the thickness is also less reproducible than these two characteristics. It can be explained by the manufacturing procedure. The slurry was dried during about a week but the air humidity could vary from one week to another. Thus, if water was not completely removed from the slurry, the real mass of copper decreases and thus, the thickness. The lack of reproducibility of the manufacturing procedure is not a problem for the present study as the parameters were measured for each sample, but a close attention should be paid to an industrial manufacturing of wicks following these procedures. 

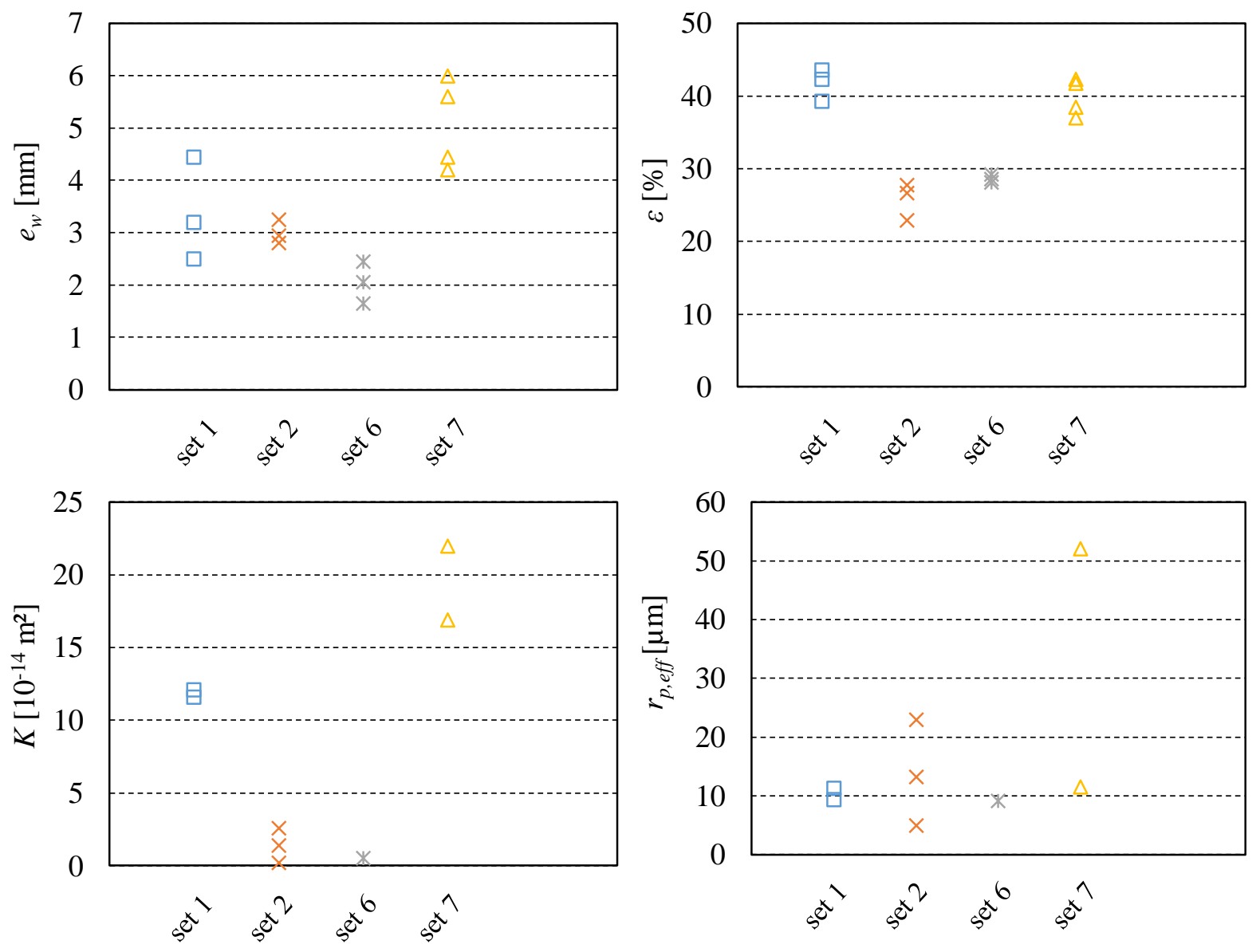

Figure 2: Thickness, porosity, permeability and effective pore radius of various porous samples

Table 2 summarises the hydrodynamic characteristics of the samples manufactured by means of the eight sets of parameters of the design of experiment. A given sample numbered $i$ was manufactured using the set of parameters numbered $i$. When several samples were manufactured with the same set $i$ of sintering parameters, the sample having the highest permeability and the lowest effective pore radius was considered. The thickness of the samples varies between $2 \mathrm{~mm}$ and $6 \mathrm{~mm}$, the porosity between $22.5 \%$ and $41.8 \%$, the permeability between $0.52 \times 10^{-14} \mathrm{~m}^{2}$ and $16.9 \times 10^{-14} \mathrm{~m}^{2}$ and the effective pore radius between less than $5 \mu \mathrm{m}$ and $18.3 \mu \mathrm{m}$. The knowledge of these values is expected to help to understand the thermal behaviour of the various wicks, which is investigated in the next section.

Table 2: Hydrodynamic characteristics of the porous wicks

\begin{tabular}{|c|c|c|c|c|c|c|c|c|c|}
\hline Sample & $P_{f}$ & $m_{s}$ & $T_{\sin }$ & $t_{\sin }$ & $e_{w}[\mathrm{~mm}]$ & $\varepsilon[\%]$ & $K\left[10^{-14} \mathrm{~m}^{2}\right]$ & $r_{p, e f f}[\mu \mathrm{m}]$ & $r_{p}[\mu \mathrm{m}]$ \\
\hline 1 & - & - & - & - & 3.2 & 39.3 & 11.6 & 11.3 & 8.4 \\
\hline 2 & + & - & - & + & 2.8 & 27.8 & 1.37 & 11.5 & 7.0 \\
\hline 3 & - & + & - & + & 5.2 & 40.6 & 10.1 & 18.3 & 10.4 \\
\hline 4 & + & + & - & - & 4.7 & 22.6 & 0.6 & $<5.0$ & 8.1 \\
\hline 5 & - & - & + & + & 2.0 & 37.0 & 10.5 & 10.3 & 6.6 \\
\hline 6 & + & - & + & - & 2.45 & 28.6 & 0.52 & 9.3 & 6.3 \\
\hline 7 & - & + & + & - & 6 & 41.8 & 16.9 & 11.5 & 9.2 \\
\hline 8 & + & + & + & + & 5.45 & 22.5 & 0.56 & 11.3 & 8.9 \\
\hline
\end{tabular}




\section{Experimental apparatus and procedure}

\subsection{Description of the experimental apparatus}

The test bench designed in order to characterise the thermal behaviour of each manufactured sample aims at reproducing the configuration and the operation of an evaporator in a flat LHP, by decoupling it from the transport lines and the condenser. It consists of a double-wall glass enclosure secured at the base by a clamping ring (Figure 3). A grooved evaporator and the wick are embedded into the cylindrical part of the base. The sealing is ensured by O-ring seals. An L-tube goes through the base wall to enable the vapour to flow from the grooves to the enclosure containing the fluid at liquid-vapour equilibrium.

The saturation temperature of the fluid is controlled by a cryogenic fluid flowing in the annular space of the enclosure from a thermostatic bath, operating from $-50{ }^{\circ} \mathrm{C}$ to $120^{\circ} \mathrm{C}$. The liquid level $H_{l}$ can be modified by opening the filling valve in order to adjust the hydrostatic pressure $\Delta P_{h s}$ applied on the wick. Two thermocouples, housed inside a stainless steel sealed shell to ensure the sealing of the system, measure the saturation temperature: one in the liquid phase $\left(T_{l}\right)$ and the other in the vapour phase $\left(T_{v}\right)$. They are as close as possible to the liquid-vapour interface, enabling to detect the presence of noncondensable gases (NCGs) if the two temperatures are different. In the present study, the saturation temperature is set to $50{ }^{\circ} \mathrm{C}$ with water and $40{ }^{\circ} \mathrm{C}$ with pentane, and the level of liquid is kept constant and equal to $3.9 \mathrm{~cm}$.

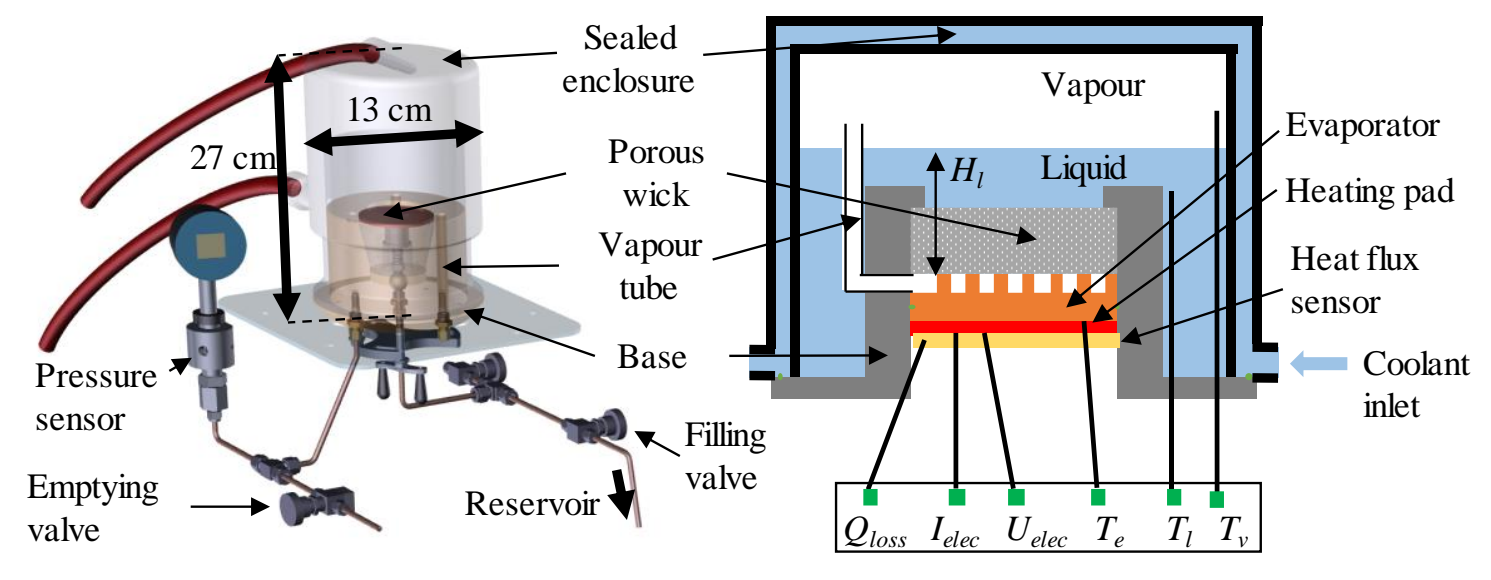

Figure 3 : Schematic of the experimental apparatus

The evaporator is made of a flat disk-shaped copper block, with a diameter of $40 \mathrm{~mm}$ and a thickness of $8 \mathrm{~mm}$. Nine $2 \mathrm{~mm}$ wide and $1.5 \mathrm{~mm}$ deep grooves were engraved in the copper block. They are separated by $1.5 \mathrm{~mm}$ thick fins. The wick is located above the grooved copper block. An exit vapour channel is machined at the grooves outlet. A thermocouple having a diameter of $80 \mu \mathrm{m}$ is located inside a $0.8 \mathrm{~mm}$ thin groove engraved in the bottom surface of the evaporator. It enables the measurement of the evaporator wall temperature. An absolute pressure sensor, which accuracy is $10^{-4}$ bar in the range from 0 to 2 bars, is used to record the saturation pressure inside the system. A heat flux ranging from 0 to $150 \mathrm{~W}\left(12 \mathrm{~W} . \mathrm{cm}^{-2}\right.$ ) is supplied by a heating element (of resistance $10.0 \Omega$ ), located between the evaporator wall and a heat flux sensor. This sensor measures the part of the heat flux lost through the back of the heat source. The heat load effectively supplied to the evaporator is determined by subtracting the lost heat power $Q_{l o s s}$ to the fixed electric power:

$$
Q_{\text {in }}=U_{\text {elec }} I_{\text {elec }}-Q_{\text {loss }}
$$

where $U_{\text {elec }}$ is the voltage and $I_{\text {elec }}$ the current intensity of the heating element. 
The heat transfer coefficient $h_{e}$ between the evaporator wall and the evaporating fluid is defined as follows:

$$
h_{e}=\frac{Q_{\text {in }}}{S_{w}\left(T_{e}-T_{s a t}\right)}=\frac{Q_{\text {in }}}{S_{w} \Delta T_{s h}}
$$

where $T_{e}$ is the evaporator wall temperature and $T_{\text {sat }}$ is the saturation temperature of the fluid, assumed equal to the vapour temperature $T_{v}$. This last assumption is not totally exact since the temperature of the liquid is subjected to a slight subcooling. This is due to the sealed enclosure geometry which requires a strong cooling of the glass wall to evacuate by condensation the heat supplied by the evaporator. The temperature difference between the evaporator wall and the fluid at saturation is called the wall superheat $\Delta T_{s h}$.

Uncertainty associated to the heat transfer coefficient was calculated by means of the error propagation theory.

$$
\frac{\delta h_{e}}{\mathrm{~h}_{\mathrm{e}}}=\sqrt{\left(\frac{\delta Q_{\text {in }}}{Q_{\text {in }}}\right)^{2}+\left(\frac{\delta S_{w}}{S_{w}}\right)^{2}+\left(\frac{\delta \Delta T_{s h}}{\Delta T_{s h}}\right)^{2}}
$$

The estimated experimental uncertainties are of about $3 \mathrm{~W}$ on the heat fluxes, $5 \%$ on the porous wick area and $1 \mathrm{~K}$ on the wall superheat. The uncertainty associated to the heat transfer coefficient can reach $30 \%$ at low heat loads, due the small temperature difference between the evaporator wall and the vapour phase and due to the small subcooling of the liquid, making difficult the estimation of the saturation temperature. At high heat loads, it decreases down to $10 \%$.

\subsection{Description of the experimental procedure}

The sealed enclosure is filled with the working fluid, preliminarily degassed. Indeed, even a small amount of NCGs may affect the heat transfer between the evaporator and the working fluid. The saturation temperature is then set at the desired value by means of the thermostatic bath. The temperature measurements of the vapour and the liquid phases are expected to be equal and to correspond to the saturation pressure recorded by the pressure sensor. If the temperature difference is higher than $3 \mathrm{~K}$, it is considered that a significant amount of NCGs is present in the sealed enclosure and the filling procedure is conducted again.

During the tests, the heat load is increased step by step, a steady state being reached before applying the next step. The test is stopped when the evaporator temperature reaches $120^{\circ} \mathrm{C}$ in order to protect the test bench materials against overheating.

Figure 4 shows an example of thermal behaviour exhibited by a manufactured sample, in which the heat transfer coefficient $h_{e}$ and the superheat $\Delta T_{s h}$ between the evaporator wall and the vapour phase are plotted as a function of the heat load. At low heat loads, the heat transfer coefficient remains constant up to a value called $Q_{o p t}$ from which it drastically decreases, leading to a large increase of the evaporator temperature $T_{e}$. The heat transfer coefficient recorded at $Q_{o p t}$ is called the optimum heat transfer coefficient $h_{e, \text { opt }}$ and the temperature difference is called the maximum superheat $\Delta T_{s h \text {, max }}$. When the heat load is greater than $Q_{o p t}$, small bubbles can sometimes be observed at the top surface of the porous structure. Clearly, an operating limit is reached at $Q_{o p t}$, leading to a degradation of the heat transfer. 


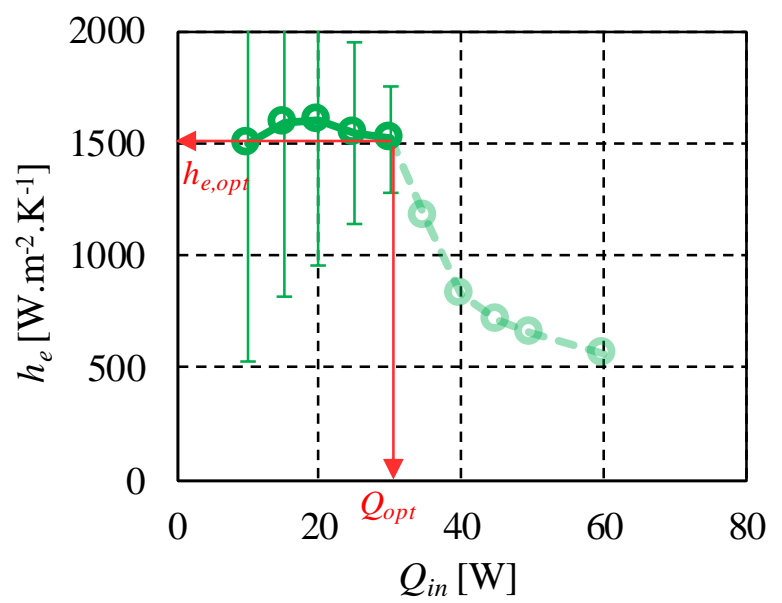

a) Heat transfer coefficient

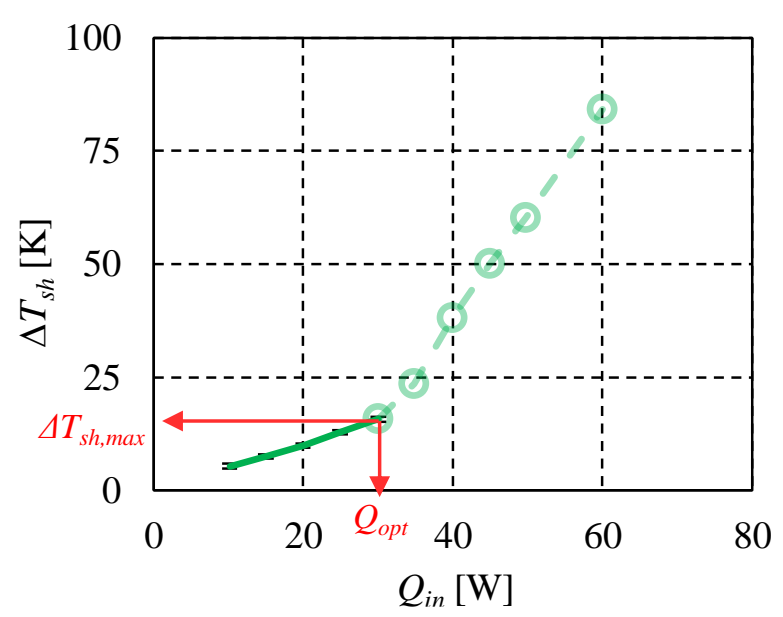

b) Evaporator superheat

Figure 4: Example of variation of the heat transfer coefficient (a) and of the evaporator superheat

(b) as a function of the heat load

\section{Theoretical operating limits of a capillary evaporator}

Various phenomena can lead to the dry-out of the evaporator. In the present test bench, the wick is likely to reach either the boiling or the capillary limit. The relationships used to predict the occurrence of both limits are described in this section.

\subsubsection{Prediction of the capillary limit}

The capillary limit is reached when the pressure drops through the wick $\Delta P_{w}$ and the vapour tube $\Delta P_{v t}$ overcome the sum of the maximum capillary pressure and the hydrostatic pressure $\Delta P_{h s}$ of the liquid column of height $H_{l}$ above the lower side of the wick (Figure 3). When the capillary limit is reached, the porous structure is no longer able to transport the liquid up to its surface. A vapour blanket partially fills the porous structure, leading to a decrease of the heat transfer coefficient and an increase of the evaporator wall temperature. The theoretical capillary limit $Q_{\text {opt,th }}$ is determined by balancing the pressure drops with the capillary force added to the hydrostatic pressure:

$$
\Delta P_{\text {cap }, \text { max }}+\Delta P_{h s}=\left.\Delta P_{w}\right|_{Q o p t, t h}+\left.\Delta P_{v t}\right|_{Q o p t, t h}
$$

The pressure drops along the vapour grooves were proven negligible. The hydrostatic pressure can be expressed as follows:

$$
\Delta P_{h s}=\left(\rho_{l}-\rho_{v}\right) g H_{l}
$$

where $\rho_{l}$ and $\rho_{v}$ are the liquid and vapour phase, respectively, and $g$ is the gravitational acceleration. The pressure drops through the wick are expressed by the Darcy's law (Eq.(2)), whereas the ones along the vapour tube can be calculated as follows:

$$
\Delta P_{v t}=\frac{\left(\beta+\alpha \frac{L_{v t}}{d_{v t}}\right) \rho_{v} u_{v}^{2}}{2}
$$

where $\beta=2.5$, is the sum of the coefficients associated to singular pressure drops at the vapour tube entrance (equal to 0.5), at the exit (equal to 1 ) and in the elbow (equal to 1). $\alpha=64 / R e$, is the friction coefficient associated to regular pressure drops along the vapour tube of length $L_{v t}$ and diameter $d_{v t}$, respectively. The vapour and liquid velocities $u_{v}$ and $u_{l}$ are determined by calculating the mass flow rate $\dot{m}$ in the circuit: 


$$
\dot{m}=\frac{Q_{\text {in }}}{h_{l v}}
$$

where $h_{l v}$ is the latent heat of vaporisation. This equation assumes that the whole heat load is transferred to the fluid by evaporation (no heat leaks to the reservoir), which is a rather strong hypothesis, since the copper-powder wick is thermally conductive. This assumption should be more precisely examined after determination of the wick effective thermal conductivity. Combining equations (7) to (10) leads to:

$$
\frac{2 \sigma \cos \theta}{r_{p, \text { eff }}}+\left(\rho_{l}-\rho_{v}\right) g H_{l}=\frac{\mu_{l} e_{w}}{K} \frac{Q_{o p t, t h}}{\rho_{l} S_{w} h_{l v}}+\frac{\left(\beta+\alpha \frac{L_{v t}}{d_{v t}}\right) \rho_{v}}{2}\left(\frac{Q_{o p t, t h}}{\rho_{v} S_{v t} h_{l v}}\right)^{2}
$$

where $S_{v t}$ is the vapour tube cross-sectional area. The resolution of this second degree equation enables to determine $Q_{o p t, t h}$, which will be compared to the experimental data. If the theoretical capillary limit is significantly higher than the experimental optimum heat load, another phenomenon is probably responsible of the dry-out.

\subsubsection{Prediction of the boiling limit}

The boiling limit is reached when the superheat between the evaporator wall and the saturation temperature of the fluid inside the porous sample is high enough so that nucleation can occur. In the present study, it is calculated using the Chi equation [25]:

$$
\Delta T_{s h, \max }=\frac{2 \sigma T_{s a t}}{\rho_{v} h_{l v}}\left(\frac{1}{r_{n}}-\frac{1}{r_{p, e f f}}\right)
$$

This equation depends on the nucleation radius $r_{n}$. Griffith and Wallis [26], who carried out many nucleation experiments with water, reported nucleation radii varying between $2.5 \mu \mathrm{m}$ and $25 \mu \mathrm{m}$. However, Chi [25] explained that in absence of NCGs, in conventional heat pipes, the nucleation radius could be as small as $0.25 \mu \mathrm{m}$. However, it is impossible to precisely know the $r_{n}$ and $r_{p}$ values at which boiling occurs. Therefore, the nucleation radius and thus, the boiling limit are only estimated in this work.

\section{Experimental results and discussions}

The influence of the hydrodynamic characteristics on the thermal behaviour of the samples is investigated in this section. To this purpose, the samples manufactured with the design of experiment are tested with water, then pentane, as working fluids.

\subsection{Thermal behaviour of the wick saturated with water}

The results of thermal characterisation obtained with water are summarised in Table 3 . The samples thickness, permeability and effective pore radius determined with the test bench described by Giraudon et $a l$. [24] are also given. Note that the porosity is not presented in this table since it has no influence on the theoretical limits. The evolution of the heat transfer coefficient is presented in Figure 5, for each sample. For the sake of clarity, only the data points before the dry-out of the wick are presented. The colour and thickness of the lines represent the permeability and the thickness of the samples. The colour of the marks represents their effective pore radius. Table 3 and Figure 5 highlights the different behaviours of the various samples. Only four samples (samples 1, 2, 3 and 7), having permeabilities higher than $1.3 \times 10^{-14} \mathrm{~m}^{2}$, operate beyond $50 \mathrm{~W}$. It could mean that in low-permeability samples (below $1.3 \times 10^{-14} \mathrm{~m}^{2}$ ), the pressure losses are too high to supply liquid to the evaporator, leading to a dry out of 
the porous structure. Thus, a high permeability is necessary to ensure good thermal performance. However, this is not sufficient because sample 5 has a high permeability but a low $Q_{o p t}$.

Table 3: Results of thermal characterisation with water

\begin{tabular}{|c|c|c|c|c|c|c|}
\hline Sample & $e_{w}[\mathrm{~mm}]$ & $\begin{array}{c}K\left[10^{-14}\right. \\
\left.\mathrm{m}^{2}\right]\end{array}$ & $\begin{array}{c}r_{p, \text { eff }} \\
{[\mu \mathrm{m}]}\end{array}$ & $Q_{\text {opt }}[\mathrm{W}]$ & $h_{e, \text { opt }}\left[\mathrm{W} \cdot \mathrm{m}^{-2} \cdot \mathrm{K}^{-1}\right]$ & $\Delta T_{\text {sh,max }}[\mathrm{K}]$ \\
\hline 1 & 3.2 & 11.6 & 11.3 & 70 & 1500 & 37.2 \\
\hline 2 & 2.8 & 1.37 & 11.5 & 100 & 2340 & 34.0 \\
\hline 3 & 5.2 & 10.1 & 18.3 & 110 & 1710 & 51.1 \\
\hline 4 & 4.7 & 0.6 & $<5.0$ & 30 & 1520 & 15.5 \\
\hline 5 & 2.0 & 10.5 & 10.3 & 50 & 1540 & 27.7 \\
\hline 6 & 2.45 & 0.52 & 9.3 & 40 & 1950 & 16.3 \\
\hline 7 & 6 & 16.9 & 11.5 & 60 & 1260 & 38.5 \\
\hline 8 & 5.45 & 0.56 & 11.3 & 20 & 480 & 46.5 \\
\hline
\end{tabular}

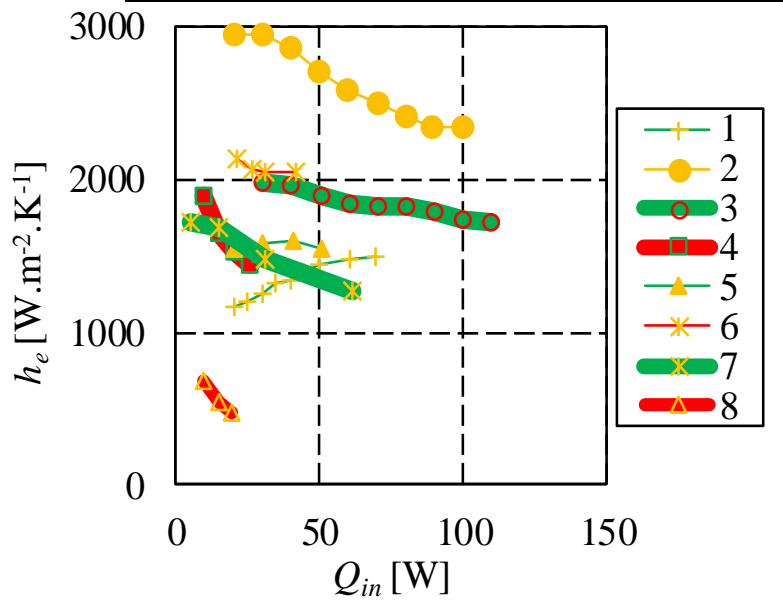

$$
\begin{aligned}
& -K>10^{-13} \mathrm{~m}^{2} \\
& -10^{-14} \mathrm{~m}^{2}<K<10^{-13} \mathrm{~m}^{2} \\
& -\quad K<10^{-14} \mathrm{~m}^{2} \\
& -\quad r_{p, \text { eff }}>13 \mu \mathrm{m} \\
& -\quad 8 \mu \mathrm{m}>r_{p, e f f}>13 \mu \mathrm{m} \\
& -\quad r_{p, \text { eff }}<8 \mu \mathrm{m} \\
& -e_{w}>4.5 \mathrm{~mm} \\
& -e_{w}<4.5 \mathrm{~mm}
\end{aligned}
$$

Figure 5: Heat transfer coefficient as a function of the heat load for each sample tested with water

The heat transfer coefficient varies in a narrow range (from 1260 to $1950 \mathrm{~W} \cdot \mathrm{m}^{-2} \cdot \mathrm{K}^{-1}$ ) except for samples 8 and 2, for which its value is much lower and much higher, respectively. The variation of $h_{e, o p t}$ can neither be explained by the permeability, nor by the thickness, nor by the pore radius. Indeed, similar values of these characteristics were found for other samples without the same consequences in terms of thermal performance. Thus, another parameter may be responsible for the difference of heat transfer coefficients between the various samples. For instance, the sample surface quality may affect the heat transfer, either through the surface roughness or through its macroscopic shape. For instance, if the samples are not perfectly flat, it may induce the presence of a gap between the wick and the evaporator fins which change the evaporation dynamics, affecting the heat transfer coefficient, as shown by Khammar et al. [6], Schertzer et al. [7], Platel et al. [27], and Figus et al. [28]. More studies and characterization technics should thus be performed to fully understand the phenomena affecting the heat transfer coefficient.

To investigate the phenomena leading to the sudden drop of the thermal performance, Figure 6 shows the experimental optimum heat flux $Q_{o p t, e x p}$ as a function of the theoretical capillary limit $Q_{o p t, t h}$, calculated by means of Eq. (11). The $Q_{\text {opt,exp }} / Q_{\text {opt,th }}$ ratio, plotted with lines, quantifies the agreement between the experimental optimum heat flux and the predicted one, a $100 \%$ ratio (plain line) corresponding to a perfect agreement. When this ratio is lower than $100 \%$, it may be an indication that the capillary limit was not reached. The calculated pressure losses are larger through the wick (a few thousands of Pascal) than through the vapour tube (a few tens of Pascal). Thus, in Eq. (11), the first term of the right member is preponderant as compared to the second term. Since the permeability of the manufactured samples varies in a larger range than the effective pore radius, the sensitivity of $Q_{o p t, t h}$ to 
$K$ is larger than its sensitivity to $\boldsymbol{r}_{\boldsymbol{p}, \text { eff }}$, for a given working fluid. In Figure 6 , the green and red marks correspond to samples having high and low permeabilities, respectively. There appear to be a correlation between the permeability range and the maximum heat flux corresponding to the capillary limit: the $Q_{\text {optexp }} / Q_{\text {opt,th }}$ ratio of samples of permeability lower than $10^{-13} \mathrm{~m}^{2}$ varies between 25 and $50 \%$. Even if it is lower than $100 \%$, this could highlight the occurrence of the capillary limit due to an early dry-out of the wick. Conversely, the $Q_{o p t, e x p} / Q_{o p t, t h}$ ratio of samples having a permeability higher than $10^{-13} \mathrm{~m}^{2}$ does not exceed $25 \%$, even $10 \%$ for the samples corresponding to the protocols 1,5 and 7 . The permeability of the latter samples is so high that the capillary limit was not reached. Another phenomenon might be responsible for the dry out.

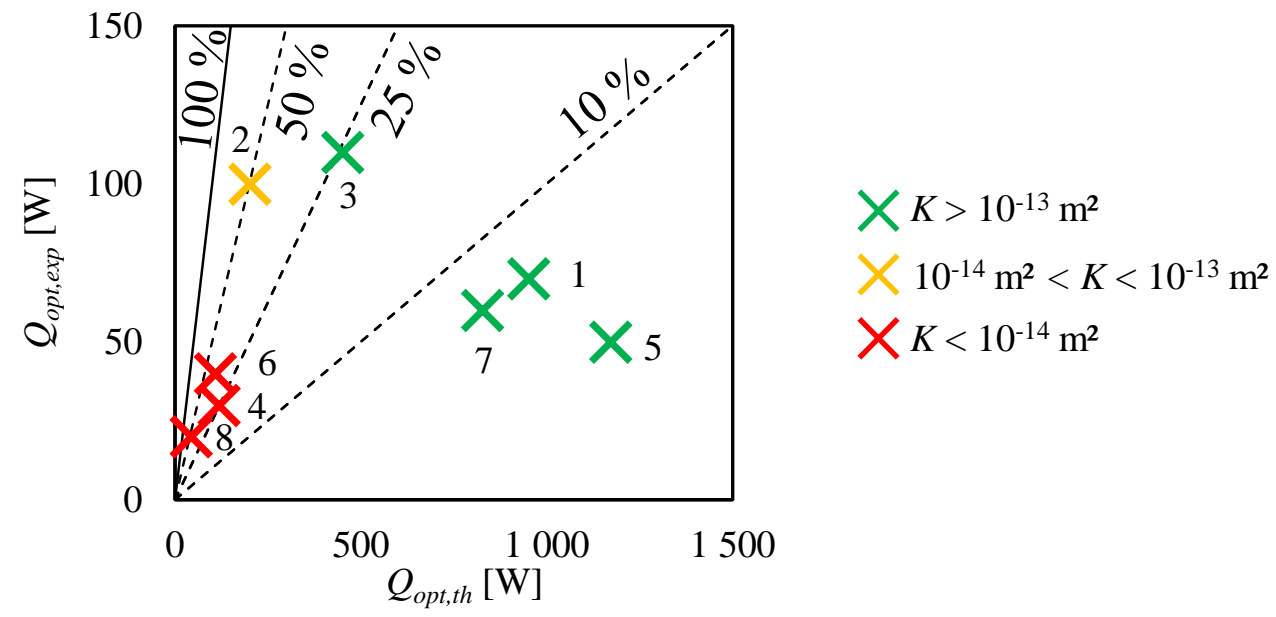

Figure 6: $Q_{o p t, e x p}$ as a function of $Q_{o p t, t h}$ for samples tested with water

In order to know if the boiling limit is reached, the same method is applied with the superheat. However, the nucleation radius being unknown, the experimental maximum superheat, $\Delta T_{s h, m a x, \text { exp }}$, is plotted with marks as a function of the effective pore radius in Figure 7. The maximum superheat calculated with Eq. (12) is also plotted on the same figure with lines, corresponding to various values of the nucleation radius. All experimental data almost correspond to a nucleation radius ranging from $3 \mu \mathrm{m}$ to $4 \mu \mathrm{m}$, which is consistent with the values found in the literature. Samples 1, 3, 5 and 7 have thus likely reached the boiling limit as they did not reach the capillary limit. As the results for samples 2,4 and 8 correspond to similar effective pore radius, they may probably also be affected by the boiling limit. Only sample 6 seems to be far from reaching the boiling limit as there is no reason for the nucleation radius to depend on the sample.

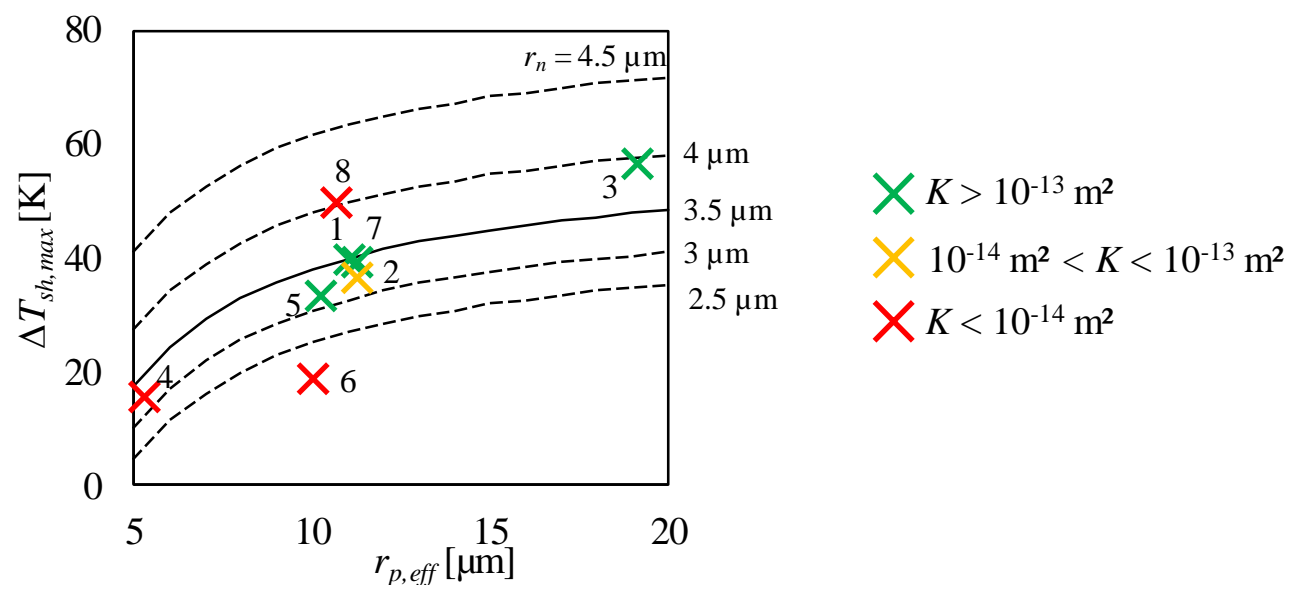

Figure 7: Experimental and theoretical maximum superheats as a function of the effective pore radius 
Considering an average nucleation radius of $3.5 \mu \mathrm{m}$, a theoretical boiling limit can be calculated for all samples. Figure 8 shows the experimental maximum superheat $\Delta T_{\text {sh,max,exp }}$ as a function of the theoretical value $\Delta T_{s h, m a x, t h}$, determined with Eq. (12). The $\Delta T_{s h, \max , \text { exp }} / \Delta T_{s h, \max , \text { th }}$ ratio, plotted with lines, quantifies the agreement between the experimental optimum superheat and the predicted one, a $100 \%$ ratio (plain line) corresponding to a perfect agreement. When this ratio is lower than $100 \%$, it may be an indication that the boiling limit was not reached. Even if the value of the theoretical boiling limit can be subjected to some debate, no correlation can be observed between the permeability and the maximum heat flux corresponding to the boiling limit: the samples having the highest probability to reach the boiling limit (i.e. 1, 3, 4, 7 and 8) are in the whole investigated permeability range.

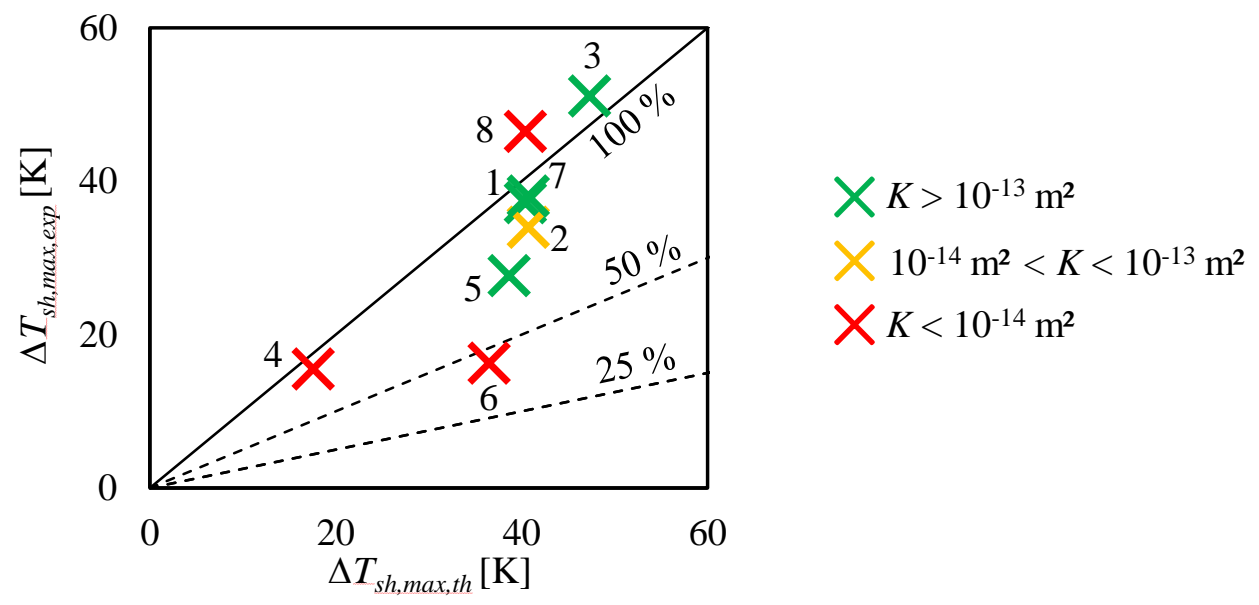

Figure 8: $\Delta T_{s h, \max , \exp }$ as a function of $\Delta T_{s h, \max , \text { th }}$ for samples tested with water $\left(r_{n}=3.5 \mu \mathrm{m}\right)$

As a conclusion, for samples 1,3,5, and 7, the probability that the boiling limit was reached is higher than the probability that the capillary limit was reached, while it is the opposite for sample 6 . For samples 2, 4 and 8, the probabilities of having observed the one or the other one of the limits are similar. Thus, in a capillary wick operating in the same conditions than a LHP wick, the capillary limit or the boiling limit may occur, preventing the system to operate at higher heat loads or higher superheats. Due to its microstructure formed by pores of small size (Figure 9b), a sample with a low permeability will probably reach the capillary limit before the boiling limit, since it prevents the fluid to easily flow through the wick. A sample with a high porosity (and thus a high permeability) has pores of larger size (Figure 9a). Since nucleation occurs at all the more low heat load as the pore size increases, it can be concluded that for samples of high permeability, the boiling limit will likely be reached earlier than the capillary limit.

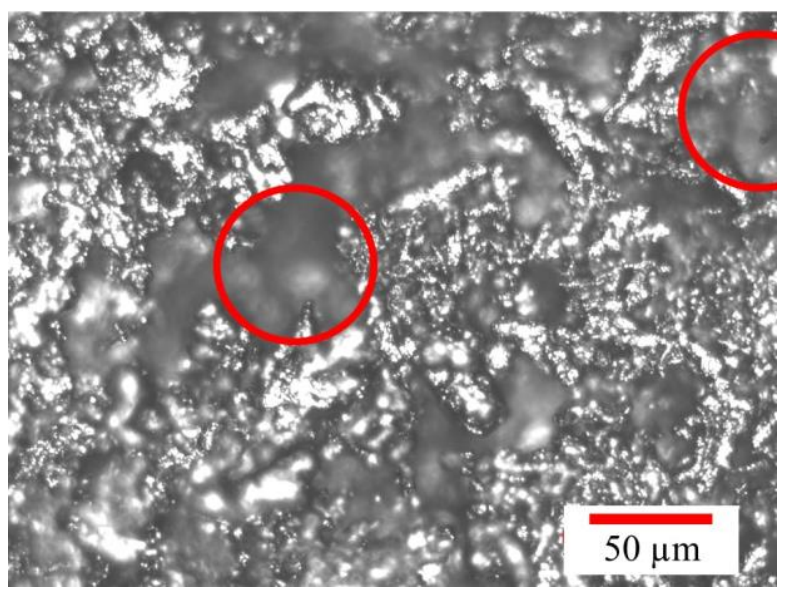

a) Sample $3\left(K=10.1 \times 10^{-14} \mathrm{~m}^{2}\right)$

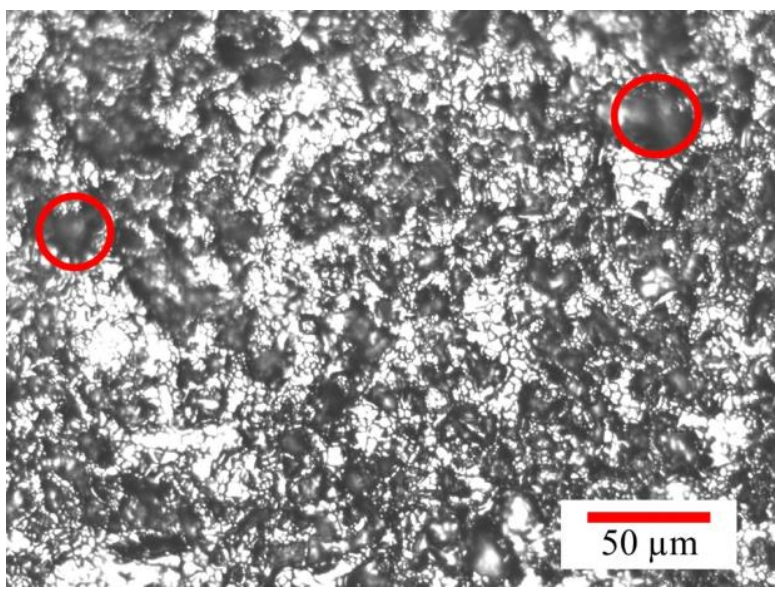

b) Sample $6\left(K=0.52 \times 10^{-14} \mathrm{~m}^{2}\right)$

Figure 9: Pictures obtained with optical microscopy. The circles highlight the largest pores of each sample 


\subsection{Thermal behaviour of the wick saturated with pentane}

The same study is conducted with pentane, to analyse the effect of the fluid properties. The results obtained with pentane (Figure 10 and Table 4) and water present many differences. Indeed, except the sample 8, all the samples have a $Q_{o p t}$ ranging from 50 to $70 \mathrm{~W}$, no matter their permeability, as shown in Table 4. Moreover, except for the sample 3, the maximum superheat is much lower than with water. However, a similarity exists with the results obtained with water: the hydrodynamic characteristics still have no evident influence on $h_{e, \text { opt }}$. The $h_{e, \text { opt }}$ values, ranging from 2060 to $5310 \mathrm{~W} \cdot \mathrm{m}^{-2} \cdot \mathrm{K}^{-1}$, are higher than the ones measured with water. This result will be discussed in the next section.

Table 4: Results of thermal characterisation with pentane

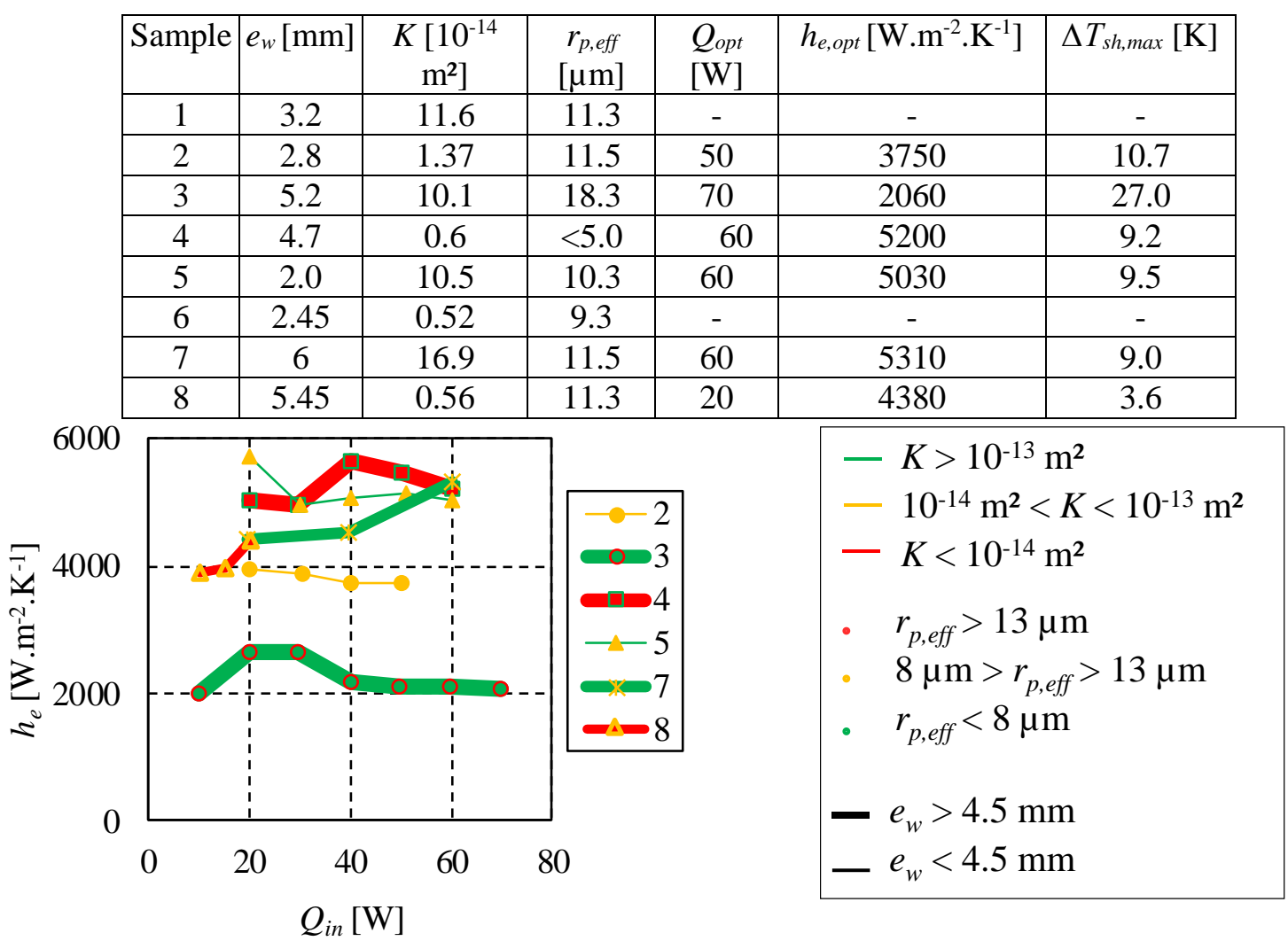

Figure 10: Heat transfer coefficient as a function of the heat load for each sample tested with pentane

The pentane properties being different from water, it is of interest to investigate again the phenomena limiting the evaporator operation. Figure 11 shows the experimental optimum heat load $Q_{\text {opt,exp }}$ as a function of the theoretical capillary limit $Q_{\text {opt,th. }}$. The observed trend is roughly the same than with water. Indeed, the high permeable samples 5 and 7 do not reach the capillary limit whereas the low permeable samples 2, 4 and 8 operate beyond $Q_{o p t, t h}$. But contrarily to the results obtained with water, four samples exceed the theoretical capillary limit. These surprising results may be explained by several phenomena. Firstly, whatever the considered working fluid, the assumption of the absence of heat leaks cannot be confirmed. It is possible that a part of the applied heat load is transferred by conduction to the reservoir. In this case, the mass flow rates of pentane and water would be lower as well as the pressure losses. Secondly, the static contact angle measured in the present study induces an uncertainty in the calculation of the theoretical capillary limit. Moreover, the minimum meniscus radius may be affected by the fluid evaporation itself. In this case, the minimum meniscus radius measured with the hydrodynamic test bench of Giraudon et al. [24] in adiabatic conditions would be not representative of the effective pore radius of the wick when tested in the present experimental set-up. The previously mentioned sources of 
errors in the prediction of $Q_{\text {opt,th }}$ were highlighted by the tests with pentane, but they may also occur in the tests with water. Another possible cause of this phenomenon is specific to pentane: a progressive dry-out could happen inside the wick just after the capillary limit is reached, which does not hinder the evaporator operation but would lead to lower thermal performance. This phenomenon was also observed by Nagano and $\mathrm{Ku}$ [29] and $\mathrm{Ku}$ and Birur [30] in heat pipes. It means that the capillary limit would be exceeded for the samples 2, 3, 4 and 8 . This explanation is supported by the average $h_{e, o p t}$ value of these samples, of only $3850 \mathrm{~W} \cdot \mathrm{m}^{-2} \cdot \mathrm{K}^{-1}$ whereas it is of $5170 \mathrm{~W} \cdot \mathrm{m}^{-2} \cdot \mathrm{K}^{-1}$ (34 \% higher) for samples 5 and 7 , for which the capillary limit is supposed not to be reached.

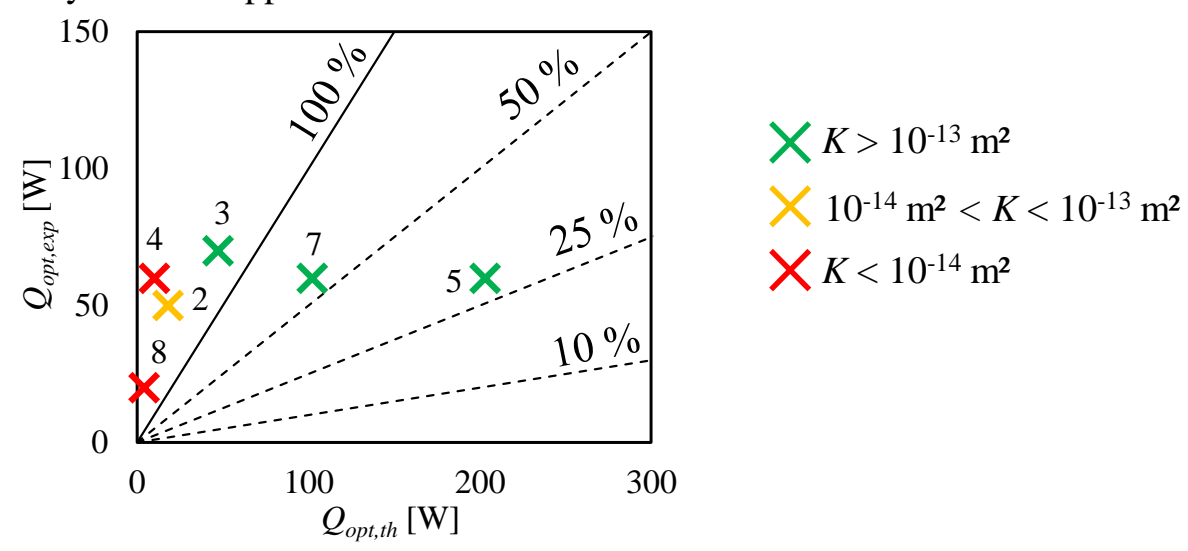

Figure 11: $Q_{\text {opt,exp }}$ as a function of $Q_{\text {opt,th }}$ for samples tested with pentane

The experimental and theoretical superheats are plotted as a function of the effective pore radius in Figure 12. Samples 2, 4, 5 and 7 reached a superheat that corresponds to a nucleation radius of around $0.7 \mu \mathrm{m}$. It is expected that the nucleation radius with pentane is lower than with water due to its lower surface tension and its higher vapour density. This result, which seems to prove that these samples have reached the boiling limit, is surprising since from Figure 11, the low permeable samples 4 and 2 were supposed to have reached the capillary limit. The superheat obtained with the sample 8 is lower than the other samples one but it is not surprising since, from Figure 11, it has probably reached the capillary limit. The sample 3 operates with a superheat which greatly exceeds the theoretical superheat corresponding to a nucleation radius of $0.7 \mu \mathrm{m}$. It means that the first nucleation site is lately activated, or that the boiling phenomenon does not prevent the operation of this specific sample. However, this particular behaviour could not be further explained. As observed for the tests with water, the samples not concerned by the capillary limit (samples 5 and 7) reached an experimental superheat consistent with the occurrence of boiling. The samples 2, 3 and 4 might also be concerned by the boiling limit, since their experimental superheats are consistent with the occurrence of boiling. However, for these samples, it cannot be decided if they have reached the capillary or the boiling limit.

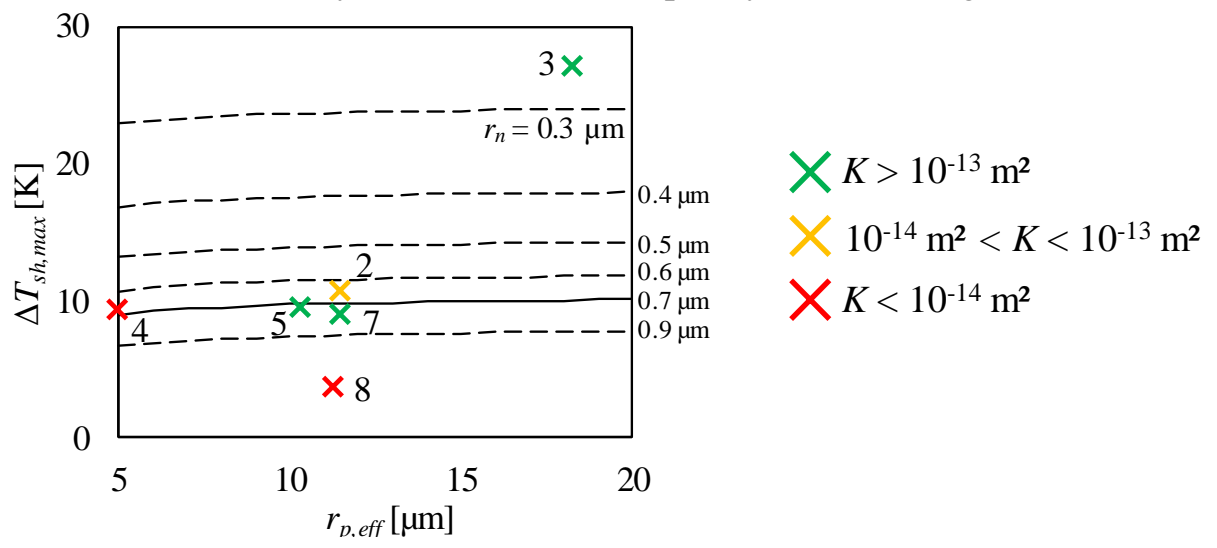

Figure 12: Experimental and theoretical maximum superheats as a function of the effective pore radius 
As a conclusion, for samples 5, and 7, the probability that the boiling limit was reached is higher than the probability that the capillary limit was reached, while it is the opposite for sample 8 . For samples 2, 3 and 4, the probabilities of having observed the one or the other one of the limits are similar.

\subsection{Comparison of the results obtained with water and pentane}

Figure 13 presents a comparison of the optimum heat flux and optimum heat transfer coefficient of the sintered copper samples obtained when using pentane and water.

It can be observed that the optimum heat flux measured with pentane varies in a narrower range than with water: except for the sample 8, it varies from 50 to $70 \mathrm{~W}$ with pentane and from 30 to $110 \mathrm{~W}$ with water. None of these two fluids leads systematically to a higher optimum heat load than the other one: the optimum heat flux is higher with pentane than with water for samples 4 and 5, identical for samples 7 and 8 , lower for samples 2 and 3. More studies are required to fully understand the difference of behaviour between these two fluids.

It can also be noted that the heat transfer coefficient is significantly higher with pentane than with water. This can be explained by the difference between the properties of these two fluids. The wettability of the pentane on oxidised copper being significantly higher than the water one, it wets more easily the wick in contact with the evaporator wall, reducing the thermal resistance.

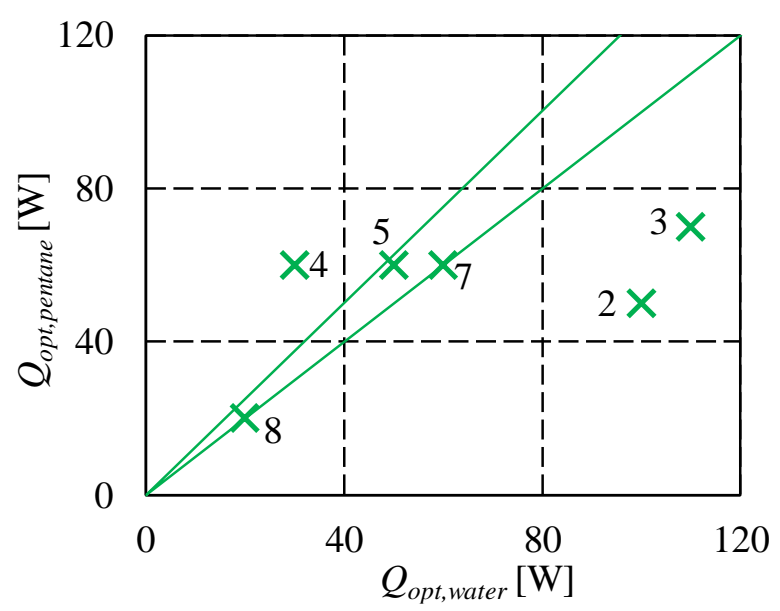

a) Optimum heat load

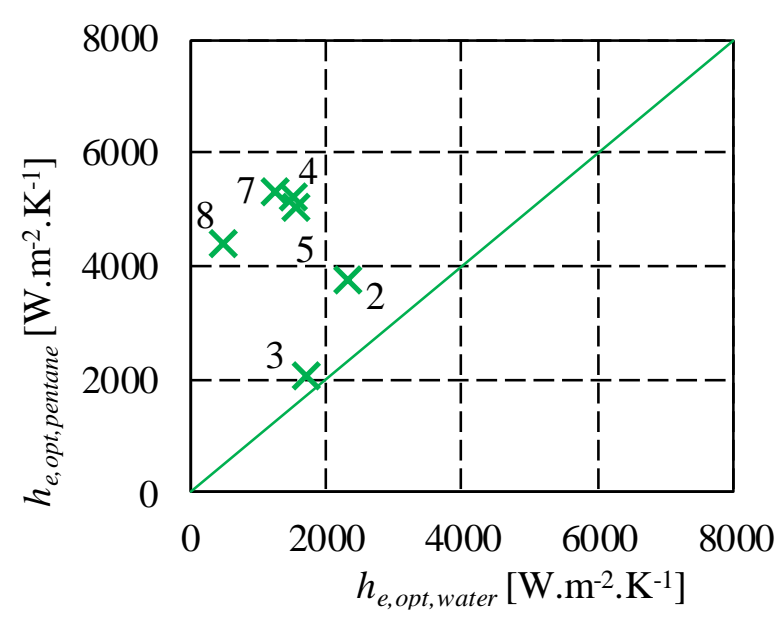

b) Heat transfer coefficient

Figure 13: Comparison of the thermal performance of the samples tested with water and pentane

\section{Conclusion}

The present experimental study is intended to better understand the thermal behaviour of an LHP evaporator, by decoupling it from the transport lines and the condenser. A test bench was proposed in order to investigate the effect of porous samples hydrodynamic characteristics, for which the manufacturing process and the characterisation are well controlled, on the evaporator heat transfer coefficient and operating limits. Several porous structures were manufactured following a specific design of experiment and characterised in terms of thickness, porosity, permeability, pore radius and static contact angle. For the thermal study, eight samples were selected which thickness, porosity, permeability and effective pore radius vary in the ranges of $2-6 \mathrm{~mm}, 22.5-41.8 \%, 0.52 \times 10^{-14}$ $16.9 \times 10^{-14} \mathrm{~m}^{2}$ and less than $5 \mu \mathrm{m}$ to $18.3 \mu \mathrm{m}$, respectively.

The analysis of the evolutions of the heat transfer coefficient $h_{e}$ and the superheat between the evaporator and the vapour phase as a function of the heat load showed that beyond a value called $Q_{o p t}$, 
$h_{e}$ drastically decreases, leading to a large increase of the evaporator wall temperature. This phenomenon evidences a wick dry-out and the occurrence of an operating limit.

The experimental optimum heat fluxes and maximum superheats were compared to theoretical models. A sample with a low permeability will probably reach the capillary limit since it prevents the fluid to easily flow through the wick whereas samples with a high porosity, corresponding to a permeability higher than $10^{-13} \mathrm{~m}^{2}$, will probably reach the boiling limit. Indeed, a low permeability prevents the fluid to flow through the wick whereas in a high permeable wick, the heat load can be increased up to reach a wall superheat leading to the boiling limit.

The investigation of the hydrodynamic characteristics influence have shown that it is often possible, knowing the permeability, the thickness and the effective pore radius, to predict the operating limits. However, no direct relationship was established between these characteristics and the heat transfer coefficient.

The fluid properties have a significant influence on the optimum heat transfer coefficient and the optimum heat flux. The most performant porous structures can evacuate heat flux densities of $88 \mathrm{~kW} \cdot \mathrm{m}^{-2}$ with water and $56 \mathrm{~kW} \cdot \mathrm{m}^{-2}$ with pentane. Heat transfer coefficients reach $2340 \mathrm{~W} \cdot \mathrm{m}^{-2} \cdot \mathrm{K}^{-1}$ with water and $5310 \mathrm{~W} \cdot \mathrm{m}^{-2} \cdot \mathrm{K}^{-1}$ with pentane. The optimum heat flux obtained with pentane varies in a smaller range than with water, but none of these fluids is better than the other one concerning the optimum heat flux. However, the heat transfer coefficient is significantly higher with pentane than with water, probably because of the higher wettability of pentane, allowing the fluid to wet more easily the wick in contact with the evaporator wall.

\section{Nomenclature}

\begin{tabular}{lll}
\multicolumn{3}{c}{ Latin symbols } \\
$d$ & diameter & $\mathrm{m}$ \\
$e$ & thickness & $\mathrm{m}$ \\
$g$ & specific free energy & $\mathrm{J} \cdot \mathrm{kg}^{-1}$ \\
$g$ & gravitational acceleration & $\mathrm{m} \cdot \mathrm{s}^{-2}$ \\
$H$ & height & $\mathrm{m}$ \\
$h$ & heat transfer coefficient & $\mathrm{W} \cdot \mathrm{m}^{-2} \cdot \mathrm{K}^{-1}$ \\
$h_{l v}$ & enthalpy of vaporisation & $\mathrm{J} \cdot \mathrm{kg}^{-1}$ \\
$I_{\text {elec }}$ & current intensity & $\mathrm{A}$ \\
$K$ & permeability & $\mathrm{m}$ \\
$L$ & length & $\mathrm{m}$ \\
$m$ & mass & $\mathrm{kg}$ \\
$\dot{m}$ & mass flow rate & $\mathrm{kg} \cdot \mathrm{s}^{-1}$ \\
$P$ & pressure & $\mathrm{Pa}$ \\
$Q$ & heat load & $\mathrm{W}$ \\
$r$ & radius & $\mathrm{m}$ \\
$S$ & surface & $\mathrm{m}$ \\
$T$ & temperature & $\mathrm{K}$ \\
$t$ & time & $\mathrm{s}$
\end{tabular}




\begin{tabular}{|c|c|c|}
\hline$U_{\text {elec }}$ & voltage & $\mathrm{V}$ \\
\hline$u$ & velocity & $\mathrm{m} \cdot \mathrm{s}^{-1}$ \\
\hline \multirow[t]{2}{*}{$V$} & volume & $\mathrm{m}^{3}$ \\
\hline & Greek symbols & \\
\hline$\alpha$ & regular pressure losses coefficient & - \\
\hline$\beta$ & singular pressure losses coefficient & - \\
\hline$\Delta$ & difference & - \\
\hline$\varepsilon$ & porosity & - \\
\hline$\mu$ & dynamic viscosity & Pa.s \\
\hline$\rho$ & density & $\mathrm{kg} \cdot \mathrm{m}^{-3}$ \\
\hline$\sigma$ & surface tension & N.m ${ }^{-1}$ \\
\hline \multirow[t]{2}{*}{$\theta$} & static contact angle & $\mathrm{rad}$ \\
\hline & Subscripts & \\
\hline cap & capillary & \\
\hline Darcy & Darcy & \\
\hline e & evaporator & \\
\hline eff & effective & \\
\hline $\exp$ & experimental & \\
\hline f & forming & \\
\hline hs & hydrostatic & \\
\hline in & input & \\
\hline 1 & liquid & \\
\hline loss & lost to the ambiance & \\
\hline $\mathrm{m}$ & meniscus & \\
\hline $\min$ & minimum & \\
\hline $\max$ & maximum & \\
\hline n & nucleation & \\
\hline opt & optimum & \\
\hline $\mathrm{p}$ & pore & \\
\hline pentane & pentane & \\
\hline s & powder particle & \\
\hline sat & saturation & \\
\hline sh & superheat & \\
\hline $\sin$ & sintering & \\
\hline $\sin k$ & heat sink & \\
\hline th & theoretical & \\
\hline $\mathrm{v}$ & vapour & \\
\hline $\mathrm{vt}$ & vapour tube & \\
\hline $\mathrm{w}$ & wick & \\
\hline water & water & \\
\hline
\end{tabular}




\section{References}

[1] J. M. Cimbala et al., 'Study of a loop heat pipe using neutron radiography', Appl. Radiat. Isot., vol. 61, pp. 701-705, 2004.

[2] J. Ku, 'Operating Characteristics of Loop Heat Pipes', in 29th International Conference on Environmental System, 1999, vol. 1999-01-2007, pp. 503-519.

[3] S. Launay, V. Sartre, and J. Bonjour, 'An analytical Model for Characterization of Loop Heat Pipes', J. Thermophys. Heat Transf., vol. 22, no. 4, pp. 623-631, 2008.

[4] T. Zhao and Q. Liao, 'On capillary-driven flow and phase-change heat transfer in a porous structure heated by a finned surface: measurements and modeling', Int. J. Heat Mass Transf., vol. 43, no. 7, pp. 1141-1155, Apr. 2000.

[5] Q. Liao and T. Zhao, 'A visual study of phase-change heat transfer in a two-dimensional porous structure with a partial heating boundary', Int. J. Heat Mass Transf., vol. 43, no. 7, pp. 1089-1102, 2000.

[6] M. Khammar, D. Ewing, C. Y. Ching, and J. S. Chang, 'Heat transfer from a surface into a confined gap over a saturated porous plate', Int. J. Heat Mass Transf., vol. 76, pp. 144$152,2014$.

[7] M. J. Schertzer, D. Ewing, and C. Y. Ching, 'The effect of gap distance on the heat transfer between a heated finned surface and a saturated porous plate', Int. J. Heat Mass Transf., vol. 49, no. 21-22, pp. 4200-4208, 2006.

[8] A. A. M. Delil and V. Baturkin, 'Miniature loop heat pipe with a flat evaporator', NLR report, NLR-TP-2002-273, 2002.

[9] L. Mottet, T. Coquard, and M. Prat, 'Three dimensional liquid and vapour distribution in the wick of capillary evaporators', Int. J. Heat Mass Transf., vol. 83, pp. 636-651, 2015.

[10] P. Kumar, B. Wangaskar, S. Khandekar, and K. Balani, 'Thermal-fluidic transport characteristics of bi-porous wicks for potential loop heat pipe systems', Exp. Therm. Fluid Sci., vol. 94, pp. 355-367, 2018.

[11] L. Jiang et al., 'Design and fabrication of sintered wick for miniature cylindrical heat pipe', Trans. Nonferrous Met. Soc. China, vol. 24, no. 1, pp. 292-301, 2014.

[12] G. Xin, P. Zhang, Y. Chen, L. Cheng, T. Huang, and H. Yin, 'Development of composite wicks having different thermal conductivities for loop heat pipes', Appl. Therm. Eng., vol. 136, pp. 229-236, 2018.

[13] C. C. Yeh, B. H. Liu, and Y. M. Chen, 'A study of loop heat pipe with biporous wicks', Heat Mass Transf., vol. 44, no. 12, pp. 1537-1547, 2008.

[14] H. Li, Z. Liu, B. Chen, W. Liu, C. Li, and J. Yang, 'Development of biporous wicks for flat-plate loop heat pipe', Exp. Therm. Fluid Sci., vol. 37, pp. 91-97, 2012.

[15] Z. Liu, H. Li, B. Chen, J. Yang, and W. Liu, 'Operational characteristics of flat type loop heat pipe with biporous wick’, Int. J. Therm. Sci., vol. 58, pp. 180-185, 2012.

[16] B. B. Chen, W. Liu, Z. C. Liu, H. Li, and J. G. Yang, 'Experimental investigation of loop heat pipe with flat evaporator using biporous wick', Appl. Therm. Eng., vol. 42, pp. 3440, 2012.

[17] B. B. Chen, Z. C. Liu, W. Liu, J. G. Yang, H. Li, and D. D. Wang, 'Operational characteristics of two biporous wicks used in loop heat pipe with flat evaporator', Int. J. Heat Mass Transf., vol. 55, no. 7-8, pp. 2204-2207, 2012.

[18] B. Yu and P. Cheng, 'A fractal permeability model for bi-dispersed porous media', Int. J. Heat Mass Transf., vol. 45, no. 14, pp. 2983-2993, 2002.

[19] Z. Q. Chen, P. Cheng, and T. S. Zhao, 'An experimental study of two phase flow and boiling heat transfer in bi-dispersed porous channels', Int. Commun. Heat Mass Transf., vol. 27, no. 3, pp. 293-302, 2000. 
[20] S.-C. Wu, C.-J. Huang, S.-H. Chen, and Y.-M. Chen, 'Manufacturing and testing of the double-layer wick structure in a loop heat pipe', Int. J. Heat Mass Transf., vol. 56, no. 1-2, pp. 709-714, 2013.

[21] J. Xu, X. Ji, W. Yang, and Z. Zhao, 'Modulated porous wick evaporator for loop heat pipes: Experiment', Int. J. Heat Mass Transf., vol. 72, pp. 163-176, 2014.

[22] X. Ji, Y. Wang, J. Xu, and Y. Huang, 'Experimental study of heat transfer and start-up of loop heat pipe with multiscale porous wicks', Appl. Therm. Eng., vol. 117, pp. 782798, 2017.

[23] D. C. Montgomery, Design and analysis of experiments. John Wiley \& Sons, 2008.

[24] R. Giraudon, S. Lips, D. Fabrègue, L. Gremillard, E. Maire, and V. Sartre, 'Design and optimization of the sintering process of a bi-layer capillary structure for loop heat pipes', Heat Pipe Sci. Technol. Int. J., vol. 8, no. 1, pp. 27-49, 2017.

[25] S. W. Chi, Heat pipe theory and practice: a sourcebook. Washington DC: Hemisphere Pub. Corp., 1976.

[26] P. Griffith and J. D. Wallis, 'The role of surface conditions in nucleate boiling', Cambridge Massachusetts Institute of Technology, Division of Industrial Cooperation, 1958.

[27] V. Platel, O. Fudym, C. Butto, and P. Briend, 'Coefficient de transfert, à l'interface de vaporisation, d'une boucle fluide diphasique à pompage thermocapillaire', Rev Gén Therm, vol. 35, pp. 592-598, 1996.

[28] C. Figus, Y. Le Bray, S. Bories, and M. Prat, 'Heat and mass transfer with phase change in a porous structure partially heated: continuum model and pore network simulations', Int. J. Heat Mass Transf., vol. 42, pp. 1446-1458, 1999.

[29] H. Nagano and J. Ku, 'Capillary limit of a multiple-evaporator and multiple-condenser miniature loop heat pipe', J. Thermophys. Heat Transf., vol. 21, no. 4, pp. 694-701, 2007.

[30] J. Ku and G. Birur, 'Capillary Limit in a Loop Heat Pipe with Dual Evaporators', SAE Technical Paper, 2002. 